DOI: http://dx.doi.org/10.12957/demetra.2014.12826

\title{
Qualidade microbiológica e físico-química de refrescos comercializados nos municípios de Barra Mansa e Volta Redonda-RJ
}

\section{Microbiological and physicochemical quality of refreshments marketed in the municipalities of Barra Mansa and Volta Redonda, state of Rio de Janeiro}

\author{
Desiane de Carvalho Moresi Brum? \\ Aline Cristina Teixeira Mallet ${ }^{\prime}$ \\ Margareth Lopes Galvão Saron \\ Elton Bicalho de Souza ${ }^{1}$ \\ Lívia Martinez Abreu Soares Costa² \\ ' Departamento de Nutrição, Centro Universitário \\ de Volta Redonda. Volta Redonda-RJ, Brasil. \\ ${ }^{2}$ Departamento de Biologia, Universidade \\ Federal de Lavras. Lavras-MG, Brasil. \\ Correpondência / Correspondence \\ Aline Cristina Teixeira Mallet \\ E-mail: a.mallet@ig.com.br
}

\section{Resumo}

Os refrescos vendidos em estabelecimentos comerciais são armazenados em refresqueiras que, se higienizadas de forma inadequada, servirão como meio de contaminação, tornando o consumidor vulnerável a doenças transmitidas por alimentos. A avaliação da qualidade microbiológica dos alimentos fornece informações que permitem avaliá-los quanto às condições de processamento, armazenamento e distribuição e aos riscos à Saúde Pública. Perante o atual consumo de refrescos e pela gravidade pressuposta pela ingestão de alimentos contaminados, este trabalho teve como objetivo avaliar a qualidade microbiológica de refrescos acondicionados em refresqueiras, comercializados nas cidades de Barra Mansa e Volta Redonda-RJ. Foram coletadas sete amostras de refrescos, em embalagens esterilizadas de 250 $\mathrm{ml}$, de estabelecimentos comerciais como lanchonetes e padarias. Para as análises microbiológicas, foram investigadas a presença de Salmonella sp e de coliformes termotolerantes; e para as análises físico-químicas, realizou-se a determinação da acidez titulável e do $\mathrm{pH}$. Das sete amostras analisadas, duas encontram-se em desacordo com os padrões estabelecidos pela legislação vigente, quanto à presença de coliformes a $45^{\circ} \mathrm{C}$ ou termotolerantes. Os resultados das análises de Salmonella sp indicaram que todas as amostras estavam de acordo com os padrões legais vigentes. Para as amostras de refresco de caju analisadas quanto a determinação da acidez titulável, $100 \%$ estavam de acordo com a legislação, mas o mesmo não foi observado para a amostra de suco de laranja (50\%). Conclui-se que $29 \%$ das amostras analisadas encontramse impróprias para consumo, podendo representar risco à saúde dos consumidores. 
Palavras-chave: Contaminação de alimentos. Coliformes. Bebidas. Manipulação de Alimentos.

\section{Abstract}

Commercially sold refreshments are stored in coolers that, if improperly cleaned, will be a means of contamination, therefore making the consumer vulnerable to foodborne diseases. The assessment of the microbiological quality of food provides information to enable its evaluate in terms of processing, storage and distribution, its useful life and risks to public health. Given the current consumption of refreshments and the assumed severity of contaminated food ingestion, this study aimed to evaluate the microbiological quality of refreshments packed in coolers, marketed in the cities of Barra Mansa and Volta RedondaRJ. We collected seven samples of refreshments, five of cashew juice and two of orange juice, in $250 \mathrm{ml}$ sterile packages, from commercial establishments such as coffee shops and bakeries. For microbiological analyzes, we investigated the presence of Salmonella sp. and fecal coliforms; and for the physicochemical analyzes, determinations of titratable acidity and $\mathrm{pH}$ were performed. Two of the seven samples were outside the norms established by the current legislation regarding the presence of coliforms at $45^{\circ} \mathrm{C}$ or thermotolerant. The Salmonella sp. analyzes results indicated that all samples were in accordance with the applicable legal standards, all samples (100\%) of cashew juice analyzed for titratable acidity, were in accordance with the law, however, this was not observed for the orange juice sample (50\%). It concluded that $29 \%$ (2) of the analyzed samples were unsuitable for consumption and may pose a health risk to consumers.

Key words: Food Contamination. Coliforms. Beverages. Food Handling.

\section{Introdução}

De acordo com Moretto, ${ }^{1}$ sucos são bebidas obtidas através de processos tecnológicos apropriados, por meio de espremedura ou extração de frutas maduras, e são compostos por açúcares, ácidos, sais minerais, vitaminas e pigmentos. Cavalcanti et al. ${ }^{2}$ acrescentam que consiste numa "mistura" aquosa de vários componentes orgânicos voláteis e instáveis, responsáveis pelo sabor e aroma do produto.

A composição dos sucos de frutas varia de acordo com a espécie, estágio de maturação, fatores climáticos e condições de cultivo das frutas. ${ }^{3}$ Ainda que a composição apresente grande variação, os principais componentes encontrados são água, carboidratos, proteínas, lipídios, ácidos orgânicos 
vitaminas e minerais. Mais de $80 \%$ das frutas é composta de água, e o teor de umidade varia durante o dia em função da temperatura. Depois da água, os carboidratos são os componentes mais abundantes, e pode variar de 2 a $4 \%$ nos tecidos de frutas. ${ }^{4}$ Outro aspecto de grande relevância é a escolha do momento adequado para a realização da colheita, já que influencia diretamente na vida útil e na qualidade final do produto. Assim, frutos colhidos muito maduros podem apresentar textura mole e sabor insípido, e frutas colhidas muito cedo ou tardiamente são mais suscetíveis a desordens fisiológicas.

O teor do suco de fruta presente na bebida é o que diferencia suco, néctar e refresco. Os sucos são compostos por $100 \%$ de fruta in natura e não contêm conservantes, adoçantes e corantes artificiais. O néctar é composto por $99 \%$ a $25 \%$ da fruta in natura, podendo conter adoçantes, corantes e conservantes. O refresco apresenta de $24 \%$ a $3 \%$ da fruta in natura, sendo que a bebida é obtida pela diluição em água potável, do suco de fruta, com ou sem adição de açúcares. ${ }^{5,6}$

Tem-se observado o aumento da comercialização de refrescos em diferentes estabelecimentos comerciais que decorre, em grande parte pelo baixo custo, variedade de sabores e boa aceitabilidade. Isto nos reporta a uma grande preocupação com a segurança alimentar do consumidor, visto que os refrescos são armazenados em refresqueiras, que se higienizadas de forma inadequada, servirão como meio de contaminação, tornando o consumidor vulnerável às doenças transmitidas por alimentos (DTA).

As DTAs constituem um dos problemas de saúde mais comuns, sendo classificadas em "infecções" e "intoxicações". As infecções resultam da ingestão de alimentos que contêm os microrganismos vivos e estes venham a crescer no interior do organismo que os ingeriu. Já as intoxicações são causadas quando se ingere um alimento que contenha toxinas, mesmo que os microrganismos tenham sido eliminados. A ingestão do alimento contendo a toxina causa a doença, cujos sintomas mais comuns são vômitos e diarreias, mas, dependendo da pessoa e da saúde, podem levar à morte. ${ }^{7}$

Aspectos como a higiene dos pontos de venda, a água utilizada para a preparação dos alimentos e para a limpeza dos utensílios, a forma de conservação e a proteção contra vetores, são quesitos de grande importância e que devem ser considerados para evitar a proliferação dos microrganismos. ${ }^{8}$

O conceito de qualidade de alimentos, na visão do consumidor, corresponde à satisfação de características como sabor, aroma, aparência, embalagem, preço e disponibilidade. Os surtos de intoxicação alimentar ocorrem porque o consumidor raramente percebe a presença de contaminações perigosas nos alimentos. ${ }^{9}$ Atualmente, os estabelecimentos envolvidos com a comercialização de alimentos devem cumprir as normas contidas nas Resoluções n ${ }^{\circ}$ 216/2004, que institui critérios higiênico-sanitários para produção de alimentos, e a n 12/2001, que estabelece os Padrões Microbiológicos Sanitários para Alimentos e determina os critérios para a conclusão e interpretação dos resultados das análises microbiológicas de alimentos destinados ao consumo humano. ${ }^{10,11}$ 
A inspeção sanitária poderá verificar os fatores de risco à ocorrência de DTAs, dentre os quais se pode destacar: falha na refrigeração dos alimentos; conservação inadequada da matériaprima e do alimento pronto; práticas inadequadas pelos manipuladores, como a falta de higiene pessoal; matéria-prima contaminada; higienização inapropriada de equipamentos e utensílios; armazenamento inadequado; utilização de água cuja potabilidade não é confiável - enfim tudo o que possa tornar a manipulação desses alimentos inadequada, tornando-o passível de contaminação. ${ }^{12}$

Diante do exposto, o presente trabalho teve como objetivo avaliar a qualidade microbiológica e físico-química de amostras de refrescos acondicionados em refresqueiras, comercializados nas cidades de Barra Mansa e Volta Redonda-RJ.

\section{Metodologia}

\section{Obtenção das amostras}

Foram coletadas sete amostras de refrescos comercializadas em sete estabelecimentos localizados nos municípios de Barra Mansa e Volta Redonda, estado do Rio de Janeiro, sendo cinco de caju e dois de laranja, armazenadas em embalagens esterilizadas de $250 \mathrm{ml}$. Posteriormente, as mesmas foram acondicionadas em caixa isotérmica, com baterias de gelo, e encaminhadas ao Laboratório de Microbiologia e Bioquímica do Centro Universitário de Volta Redonda (UniFOA), para realização de análises microbiológicas e físico-químicas.

\section{Análises microbiológicas}

Para contagem de coliformes a $35^{\circ} \mathrm{C}$ e termotolerantes, utilizou-se a técnica do número mais provável (NMP), empregando três séries de três tubos. O teste presuntivo foi constituído pela homogeneização de $1 \mathrm{ml}$ de cada amostra em $9 \mathrm{ml}$ de água peptonada (0,1\%). Em seguida, foram realizadas diluições seriadas em água peptonada a $0,1 \%$. Alíquotas de $1 \mathrm{ml}$ das diluições apropriadas foram semeadas em caldo lauril sulfato triptose e incubadas a $35^{\circ} \mathrm{C}$ por 24-48 horas. Após esse período, os tubos positivos, com apresentação de gás e turvação, foram transferidos para tubos contendo caldo verde brilhante (VB) e incubados a 37으 por 24-48 horas, sendo essa etapa o teste confirmativo dos tubos positivos. Para o teste presuntivo, alíquotas de cultura dos tubos positivos em caldo VB foram transferidas com auxílio de alça de níquel cromo para tubos contendo caldo de Escherichia coli (EC), que foi incubado a $45^{\circ} \mathrm{C}$ por $24-48$ horas, constituindo o teste para a determinação do NMP de coliformes termotolerantes presentes na amostra. Os resultados foram analisados de acordo com as diluições e a quantidade de amostras positivas do teste confirmativo, orientando-se pelo uso da tabela de NMP da Bacteriological. ${ }^{13}$ 
Para a determinação de Salmonella sp, retirou-se assepticamente uma porção de $25 \mathrm{ml}$ da amostra de refresco, adicionando-a em $225 \mathrm{ml}$ de água peptonada tamponada. Posteriormente, a amostra foi incubada a $37^{\circ} \mathrm{C}$ por 24 horas (fase de pré-enriquecimento). Na sequência, realizou-se a etapa do enriquecimento seletivo, em que se transferiu $0,1 \mathrm{ml}$ desta diluição para um tubo de ensaio contendo $10 \mathrm{ml}$ de caldo tetrationato, incubado a $37^{\circ} \mathrm{C}$ por 24 horas, sendo $1 \mathrm{ml}$ transferido para um tubo contendo caldo rapapport, incubando a $42^{\circ} \mathrm{C}$ por 24 horas. A partir dos tubos dos caldos anteriores, retirou-se uma alçada de cada um dos pré-enriquecimentos e inoculou-se em duas placas de Petri, contendo os meios Salmonella-Shigella (SS) e Hecktoen entérico (He). Estas foram incubadas a $35^{\circ} \mathrm{C}$ por 24 horas. Passado esse período, caso surgissem colônias típicas, as amostras seriam encaminhadas para realização de provas bioquímicas confirmatórias. ${ }^{13}$

As análises do $\mathrm{pH}$ e da acidez foram determinadas em duplicata, segundo o Intituto Adolfo Lutz. ${ }^{14}$ Para a determinação do $\mathrm{pH}$, utilizou-se um medidor digital da Marca Sppencer scientific SP3611. Para a acidez, o filtrado foi titulado com solução de hidróxido de sódio 0,1 N em presença de fenolftaleína, sendo o resultado expresso em gramas de ácido cítrico por 100 gramas da amostra.

\section{Resultados e discussão}

Os resultados das análises microbiológicas das amostras de refrescos estão descritos na tabela 1.

Tabela 1. Resultados das análises microbiológicas das amostras de refrescos do município de Volta Redonda-RJ, 2014.

\begin{tabular}{|c|c|c|c|c|}
\hline \multirow[t]{2}{*}{ Amostras } & \multicolumn{3}{|c|}{ Coliformes a $35^{\circ} \mathrm{C}$ e Termotolerantes $\left(45^{\circ} \mathrm{C}\right)(\mathrm{NMP} / \mathrm{mL})^{*}$} & \multirow[t]{2}{*}{ Salmonella } \\
\hline & Lauril & $\mathrm{VB}^{* *}$ & $\mathrm{EC} * * *$ & \\
\hline $\mathbf{A}$ & $2,4 \times 10^{2}$ & $2,4 \times 10^{2}$ & $9,3 \times 10$ & Ausência \\
\hline B & $1,5 \times 10^{2}$ & $1,5 \times 10^{2}$ & $9,3 \times 10$ & Ausência \\
\hline $\mathbf{C}$ & $>1,1 \times 10^{3}$ & $>1,1 \times 10^{3}$ & $>1,1 \times 10^{3}$ & Ausência \\
\hline D & $2,4 \times 10^{2}$ & $2,4 \times 10^{2}$ & $2,4 \times 10^{2}$ & Ausência \\
\hline $\mathbf{E}$ & $1,5 \times 10^{2}$ & $1,5 \times 10^{2}$ & $2,3 \times 10$ & Ausência \\
\hline $\mathbf{F}$ & $4,3 \times 10$ & $4,3 \times 10$ & $4,3 \times 10$ & Ausência \\
\hline $\mathbf{G}$ & $<3,0$ & $<3,0$ & $<3,0$ & Ausência \\
\hline
\end{tabular}

* número mais provável ** caldo verde brilhante *** caldo Escherichia coli 
Das sete amostras analisadas duas (29\% - C; D) encontravam-se em desacordo com os padrões estabelecidos pela legislação vigente quanto à presença de coliformes a $45^{\circ} \mathrm{C}$ ou termotolerantes, que estabelece como limite superior $10^{2} \mathrm{UFC} / \mathrm{ml}$ em amostras de refrescos, ${ }^{11}$ evidenciando que as mesmas se apresentavam impróprias para o consumo (figura 1).

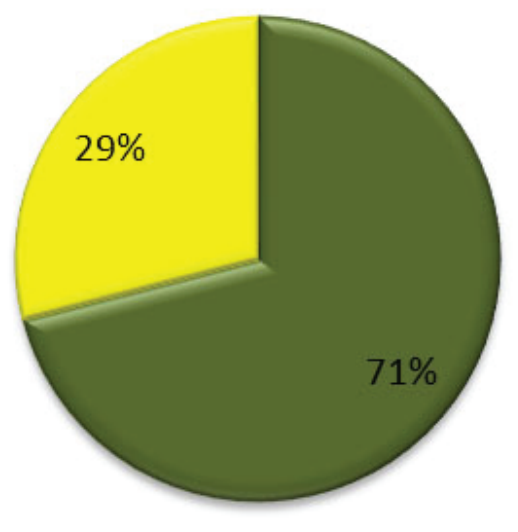

a Coliformes $45^{\circ} \mathrm{C}$ dentro do limite estabelecido pela $\operatorname{RDC}$ 으 12/2001

$\checkmark$ Coliformes $45^{\circ} \mathrm{C}$ acima do limite estabelecido pela $\operatorname{RDC} \mathrm{n}$ - 12/2001

Figura 1. Resultados das amostras com Coliformes $45^{\circ} \mathrm{C}$ dos refrescos coletados. Volta RedondaRJ, 2014,

Os resultados corroboram alguns achados da literatura. Garcia et al. ${ }^{15}$ verificaram que de 12 amostras de sucos analisadas, duas apresentavam coliformes a $45^{\circ} \mathrm{C}$ acima do permitido pela legislação. De forma similar Silveira et al. ${ }^{16}$ observaram, em sua pesquisa por coliformes termotolerantes em suco de laranja, que das cincoamostras analisadas, duas estavam em condições impróprias para consumo. Hoffmann et al. ${ }^{17}$ observaram que das 19 amostras de sucos frescos de laranja integral analisadas, três apresentaram coliformes termotolerantes. Oliveira et al. ${ }^{18}$ concluíram que das 50 amostras de suco de laranja in natura analisadas, oito estavam em desacordo com a legislação vigente.

Em relação às análises de Salmonella sp, os resultados demonstraram ausência em todas as amostras. Os resultados aqui apresentados vão ao encontro dos achados de Silveira et al. ${ }^{16} \mathrm{e}$ Pinheiro et al., ${ }^{19}$, que observaram ausência de Salmonella sp em suas amostras. Entretanto, Garcia et al. ${ }^{15}$ relataram que todas as amostras de sucos analisadas em sua pesquisa estavam contaminadas por Salmonella sp, estando, portanto, impróprias para consumo. 
Shinohara et al. ${ }^{20}$ relataram que a Salmonella é uma bactéria causadora de doenças em humanos e animais, através do consumo e da ingestão de alimentos contaminados. Os alimentos mais comumente envolvidos na contaminação por Salmonella sp são carnes, ovos, frangos, maionese caseira e hortaliças $\mathrm{O}$ período de incubação é de 12 a 72 horas, predominando sintomas a diarreia, cólica, febre e vômito. ${ }^{15}$ Os indivíduos doentes ou portadores contaminam ambientes, a água potável e os alimentos através de suas fezes, que estão infectadas por essas bactérias. ${ }^{5}$ Uma forma prática para evitar a contaminação é a realização de boas práticas de manipulação dos alimentos. ${ }^{7,21}$

Segundo Kraemer, ${ }^{22}$ para garantia de alimentos seguros, os órgãos de inspeção e fiscalização sanitária devem exigir a adoção de programas de boas práticas, como as de fabricação (BPF), agrícolas (BPA) e de higiene (BPH).

Os Procedimentos Operacionais Padronizados (POPs), que são estabelecidos pela Resolução RDC no 275, de 21 de outubro de 2002, ${ }^{23}$ representam uma ferramenta para minimizar risco e evitar possíveis causas de Doenças Transmitidas por Alimentos (DTAs). É um documento que expressa o planejamento do trabalho, devendo ser disponibilizado a todos os funcionários. $\mathrm{O}$ serviço de alimentação conta com quatro POPs, voltados diretamente para os procedimentos de higienização do reservatório de água, de áreas, equipamentos, móveis e utensílios, para o combate às pragas nos estabelecimentos e a higiene e a saúde do manipulador. ${ }^{24,25}$

Santos Junior, ${ }^{26}$ em pesquisas aplicadas no segmento alimentício, relata que $50 \%$ destes estabelecimentos não possuíam manuais e, dentre os que possuíam, a maioria permanecia em poder do proprietário ou gerente, dificultando o acesso destes documentos pelos demais funcionários.

Na tabela 2, estão apresentados os resultados das análises de $\mathrm{pH}$ e acidez das amostra de refrescos.

Tabela 2. Média dos resultados das análises de $\mathrm{pH}$ e acidez das amostras de refrescos do município de Volta Redonda-RJ, 2014.

\begin{tabular}{ccc}
\hline Amostras & $\mathrm{pH}$ & Acidez (\%) \\
\hline A & 3,70 & 0,11 \\
B & 4,7 & 0,13 \\
C & 4,0 & 0,15 \\
D & 3,49 & 0,11 \\
E & 3,49 & 0,07 \\
F & 3,45 & 0,29 \\
G & 3,47 & 0,11 \\
\hline
\end{tabular}


A maioria (86\%) das amostras analisadas para determinação da acidez titulável estava em consonância com a legislação, ${ }^{27}$ que preconiza acidez de no mínimo $0,07 \mathrm{~g}$ ácido cítrico/100ml para o refresco de caju. Outrossim, o mesmo não foi observado para a amostra C, refresco de laranja, que não se apresentava de acordo com a legislação que estipula a acidez de no mínimo 0,25 g em ácido cítrico/100ml para o referido refresco (figura 2).

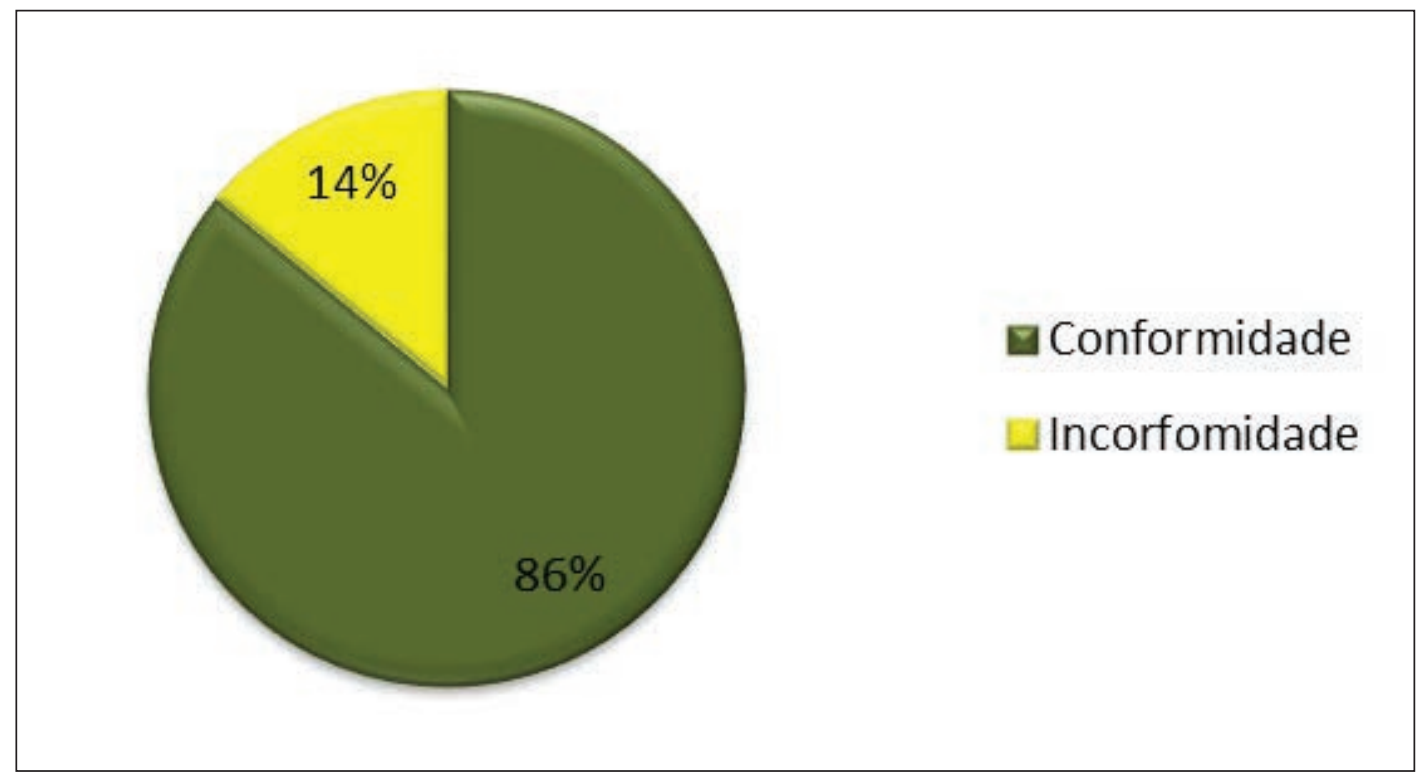

Figura 2. Resultados para determinação da acidez titulável das amostras dos refrescos coletados conforme a Portaria no 544/98. Volta Redonda-RJ, 2014.

Os valores de $\mathrm{pH}$ das amostras de refrescos de caju variaram de 3,47 a 4,70; e as de refresco de laranja, de 3,45 a 4,00. De forma similar ao presente estudo, Pinheiro et al.$^{19}$ verificaram o pH e a acidez dos sucos de caju integrais, encontrando valores entre 3,17 a 4,06 para o $\mathrm{pH}$, e 0,45 a $1,26 \mathrm{~g} / 100 \mathrm{~g}$ para a acidez.

Apesar de o pH não ser um parâmetro exigido pela legislação, é importante avaliá-lo, pois está diretamente relacionado com a qualidade do produto. De acordo com Forsythe, ${ }^{28}$ o $\mathrm{pH}$ neutro inibe a multiplicação dos principais patógenos de origem alimentar. 


\section{Conclusões}

Conclui-se que, apesar das irregularidades observadas, como a presença de coliformes em algumas amostras, e a acidez inadequada em um refresco de laranja, a maioria das amostras avaliadas encontrava-se própria para o consumo humano em relação às análises físico-químicas e microbiológicas.

\section{Agradecimentos}

Agradecemos, em especial, ao Centro Universitário de Volta Redonda (UniFOA) pelo financiamento para a condução da pesquisa e a todos os técnicos que nos auxiliaram no decorrer do experimento.

\section{Referências}

1. Moretto E, Fett, R, Gonzaga LV, Kuskoski, E. M. Introdução à ciência de alimentos. 2 ed. Florianópolis: Editora da UFSC; 2008. p.197-201.

2. Cavalcanti AL, Oliveira KF, Paiva OS, Dias MVR, Costa SKP, Vieira FF. Determinação dos sólidos solúveis totais ( ${ }^{\circ}$ Brix) e $\mathrm{pH}$ em bebidas lácteas e sucos de frutas industrializados. Pesq. Bras. Odontoped. Clin. Integr. João Pessoa 2006; 6(1):57-64.

3. Souza APF, Martins CM, Badaró ACL. Análise das características microbiológicas do suco de manga comercializado em Ipatinga- MG, em relação aos diferentes tipos de embalagens. Nutrir Gerais: Revista Digital de Nutrição 2009; 3(4):299-311.

4. Koblitz MGB. Matérias primas alimentícias: composição e controle de qualidade. Rio de Janeiro: Guanabara Koogan; 2014.

5. Ferreira EDO, Campos LC. Salmonella. In: Trabulsi LR, Alterthum F. Microbiologia. 5 ed. São Paulo: Atheneu; 2008. p. 329-338.

6. Venâncio AA, Martins OA. Análise química de diferentes marcas de néctares e suco de laranja comercializada na cidade de Cerqueira César - São Paulo. Revista Eletrônica de Educação e Ciência (REEC) 2012; 2(3):45-50.

7. Lopes FNO, Madokoro RY, Martins VF. Análises de conservação de alimentos à venda em lanchonetes da UNICAP [Internet]. Revista Ciência do Ambiente Online 2010; 6(1):

8. Cardoso RCV, Santos SMC, Silva EO. Comida de rua e intervenção: estratégias e propostas para o mundo em desenvolvimento. Ciên. Saúde Coletiva 2009; 14(4):1215-1224. 
9. Rougemont AJ. Alimentos seguros: necessidade ou barreira comercial. Perspectiva Online 2007; $1(2): 62-70$.

10. Brasil. Resolução RDC n²16, de 15 de setembro de 2004. Dispõe sobre Regulamento Técnico de Boas Práticas para Serviços de Alimentação. Diário Oficial da União 16 set. 2004. [acesso em: 20 jan. 2014]. Disponível em: http://www.mds.gov.br/acesso-a-informacao/legislacao/segurancaalimentar/ resolucoes/2004/Resolucao\%20RDC\%20no\%2021

11. Brasil. Resolução RDC no 12, de 02 de janeiro de 2001. Aprova o Regulamento Técnico sobre padrões microbiológico para alimentos. Diário Oficial da União 10 jan. 2001. [acesso em 27 fev. 2014]. Disponível em: http://portal.anvisa.gov.br/wps/wcm/connect/a47bab8047458b909541d53fbc4c6735/ RDC_12_2001.pdf?MOD=AJPER.

12. Sergipe. Prefeitura Municipal. Análise dos riscos sanitários do comércio ambulante de alimentos no pré-caju 2008. Aracaju: Coordenação de Vigilância Sanitária; 2008. [acesso em: 13 dez. 2014]. Disponível em: http://www.aracaju.se.gov.br/userfiles/covisa/precaju_final.pdf

13. Silva N, Junqueira VCA, Silveira NF. A. Manual de métodos de análise microbiológica de alimentos. São Paulo: Livraria Varela; 2007. 105 p.

14. Instituto Adolfo Lutz. Normas analíticas do Instituto Adolfo Lutz. Métodos químicos e físicos para análise de alimentos. v. 1.3 ed. São Paulo: Instituto Adolfo Lutz; 1985.

15. Garcia RCG, Santos DC, Oliveira ENA, Josino AS, Mori E. Qualidade microbiológica de sucos in natura comercializados na cidade de Juazeiro do Norte- CE. Revista Brasileira de Tecnologia Agroindustrial 2012; 6(1):665-670.

16. Silveira MLR, Bertagnolli SMM. Avaliação microbiológica e das condições higiênico-sanitárias de comercialização de sucos de laranja in natura. Alim. Nutr. 2012; 23(3):461-466.

17. Hoffmann FL, Garcia-Cruz CH, Vinturim TM, Pazzoti GSO. Qualidade microbiológica de diferentes marcas comerciais de suco de laranja integral. B. CEPPA 1998; 16(1):99-106.

18. Oliveira JC, Setti-Perdigão P, Siqueira KAG, Santos AC, Miguel MAL. Características microbiológicas do suco de laranja in natura. Cienc. Tecnol. Aliment. 2006; 26(2):241-245.

19. Pinheiro AM, Fernandes AG, Fai AEC, Prado GM, Sousa PHM, Maia GA. Avaliação química, físico-quimica e microbiológica de sucos de frutas integrais, abacaxi,caju e maracujá. Ciênc. Tecnol. Aliment. 2006; 26(1):98-103.

20. Shinohara NKS, Barros VB, Jimenez SMC, Machado ECL, Dutra RAF, Lima Filho JL. Salmonella spp., importante agente patogênico veiculado em alimentos. Ciên. Saúde Coletiva 2008; 13(5):1675-1683.

21. Manzalli PV. Manual para serviços de alimentação: implementação, boas práticas, qualidade e saúde. 2 ed. São Paulo: Metha; 2010.

22. Kraemer FB, Aguiar OBD. Segurança alimentar e nutricional na perspectiva da segurança sanitária. In: Schneider OMF. Segurança alimentar e nutricional: tecendo a rede de saberes. Petrópolis: DP et Alii; Rio de Janeiro: Faperj; 2012. p. 139-159. 
23. Brasil. Resolução RDC n 275, de 21 de outubro de 2002. Dispõe sobre o Regulamento Técnico de Procedimentos operacionais padronizados aplicados aos Estabelecimentos Produtores/ Industrializadores de Alimentos e a Lista de Verificação de Boas Práticas de Fabricação em Estabelecimentos Produtores/Industrializadores de Alimentos. Diário Oficial da União 23 set. 2005. [acesso em 22 fev. 2014]. Disponível em: http://portal.anvisa.gov.br/wps/wcm/connect/ c8b2040047457a8c873cd73fbc4c6735/RDC_276_2005.pdf?MOD=AJPERES

24. Castro Neto N, Lopes TH. Higiene e manipulação dos alimentos. Curitiba: Livro Técnico; 2012.

25. Pereira L, Pibheiro AN. Boas práticas na manipulação de alimentos. $4^{a}$ reimpr. Rio de Janeiro: Editora Senac; 2013.

26. Santos Junior, CJD. Manual de BPF, POP e registros em estabelecimentos: guia técnico para elaboração. Rio de Janeiro: Rubio; 2011.

27. Brasil. Portaria no 544, de 16 de novembro de 1998. Regulamento Técnico para fixação dos padrões de identidade e qualidade para refresco. Diário Oficial da União 17 nov. 1998; 1:90. [acesso em 27 fev. 2014]. Disponível em: http://www.engetecno.com.br/port/legislacao/beb_rtfiq_refresco.htm

28. Forsythe SJ. Microbiologia da segurança dos alimentos. 2 ed. Porto Alegre: Artmed; 2013.

Recebido: $14 / 9 / 2014$

Revisado: 20/10/2014

Aprovado: 17/11/2014 
